(1)

CrossMark

\title{
Serotonergic antidepressants in COPD: beneficial or harmful?
}

\author{
Abebaw Mengistu Yohannes \\ Affiliation: School of Behavioral and Applied Sciences, Dept of Physical Therapy, Azusa Pacific University, \\ Azusa, CA, USA. \\ Correspondence: Abebaw Mengistu Yohannes, School of Behavioral and Applied Sciences, Dept of Physical \\ Therapy, Azusa Pacific University, 701 East Foothill Boulevard, Azusa, CA 91702, USA. E-mail: ayohannesdapu.edu
}

@ERSpublications

Antidepressants are associated with elevated risk of hospitalisation and mortality. This underscores that the importance of having a collaborative care and patient-centred approach to manage depression in patients with COPD is worthy of consideration. http://ow.ly/BNkT30kGMqq

Cite this article as: Yohannes AM. Serotonergic antidepressants in COPD: beneficial or harmful? Eur Respir J 2018; 52: 1801095 [https://doi.org/10.1183/13993003.01095-2018].

Chronic obstructive pulmonary disease (COPD) affects $>174$ million people and is now the third leading cause of death worldwide [1]. In 2011, in the European Union alone, the costs of COPD (including both direct and indirect costs, and lost productivity due to increased disability-adjusted life-years) exceed $€ 141$ billion $[2,3]$.

Depression affects $\sim 40 \%$ of patients with COPD [4]. One in four individuals with COPD with depression will experience a chronic course of illness [5]. Inadequately treated depression is often associated with increased physical disability, impaired quality of life, social isolation, poor adherence to medical treatment, emergency healthcare utilisation, increased length of hospital stay and dependency on caregivers [4-7]. In addition, patients with COPD and concomitant major depression are disproportionately from a lower socioeconomic status, and exhibit higher rates of substance abuse disorders and significantly more comorbidities [4-6]. Depression in patients with COPD was associated with increases in both 30- and 60 -day hospital readmission rates $[8,9]$, and prior exacerbations predict both future exacerbations and an increased length of hospital stay [5, 8, 9]. In addition, factors associated with excessive mortality in patients with COPD include sociodemographic, behavioural and clinically relevant disease severity markers as shown in table $1[10-21,23,24]$.

The UK National Institute for Health and Care Excellence guideline for the management of depression in older adults recommends either selective serotonin reuptake inhibitors (SSRIs) or serotonin-noradrenaline reuptake inhibitors (SNRIs) as the first line of therapy for moderate-to-severe depression in patients with physical illnesses, including COPD [25]. Serotonergic antidepressants have better safety records and fewer adverse events than tricyclic antidepressants. However, the efficacy of serotonergic antidepressants in the treatment of major depression in patients with COPD remains controversial [26].

In this issue of the European Respiratory Journal, Vozoris et al. [27] present their examination of administrative data from a population of 131718 older adults (aged $\geqslant 66$ years) with a validated diagnosis of COPD. They compared new users of SSRIs or SNRIs among 118611 community-dwelling individuals and 13107 long-term care home residents with COPD to SSRI or SNRI nonusers by propensity score matching. Compared to nonusers, new users experienced a higher risk of hospitalisation (15\%), emergency care visits (13\%), COPD or pneumonia-related mortality (26\%), and all-cause mortality (20\%). In addition, respiratory-related and all-cause mortality rates were significantly higher among long-term care 
TABLE 1 Sociodemographic, behavioural and clinically relevant markers are associated with elevated risk of mortality in patients with chronic obstructive pulmonary disease (COPD)

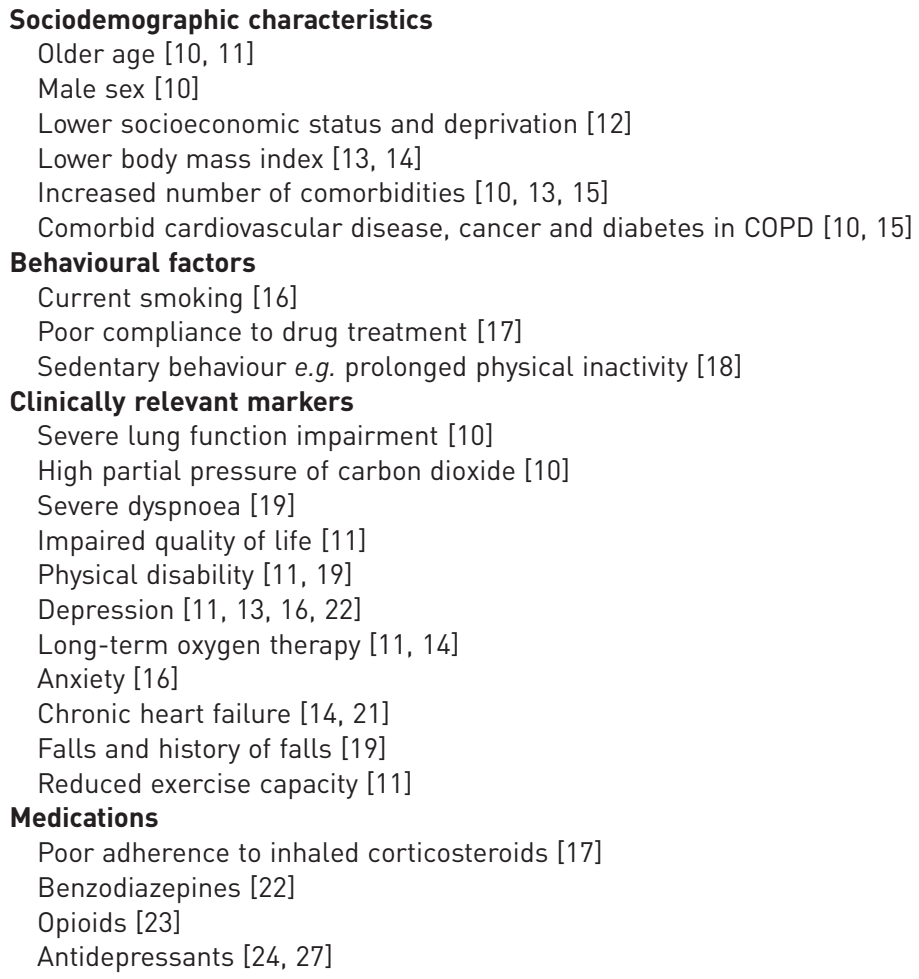

home residents newly starting SSRI/SNRI drugs compared to controls. In contrast, there was a significantly decreased rate of outpatient exacerbations among SSRI/SNRI users and no significant association with intensive care admissions during hospitalisations for COPD or pneumonia.

Importantly, in the subgroup of individuals with no exacerbations in the year prior to initiating new drug therapy, the new SSRI/SNRI users had significantly decreased outpatient exacerbations compared to nonusers. In surprising contrast, individuals with one or more exacerbation requiring hospitalisation in the year prior to index had a significantly increased rate of hospitalisation and COPD-related mortality among the new users. However, these associations (i.e. more hospitalisations and greater mortality) did not extend to patients with a COPD exacerbation in the 30 days prior to initiating new drug therapy.

What do these findings mean to prescribers and healthcare professionals who care for COPD patients with comorbid depression? Firstly, VozoRIs et al. [27] should be congratulated for sterling work that draws our attention to the small, but clinically significant, elevated risk of adverse events (e.g. hospitalisation and mortality) after initiation of a SSRI/SNRI. These findings highlight the importance of a meticulous approach to treating patients with COPD and major depression when prescribing antidepressants, including an explanation of both the concomitant conditions and the potential adverse events of therapy. In addition, it is a timely reminder not to deny patients from valuable antidepressant drug therapy, with clinically relevant salutary outcomes in other chronic diseases with concomitant major depression [28, 29]. Since an SSRI/SNRI is not a panacea, healthcare professionals must be vigilant, embrace the challenges of this important therapy, and exercise patient-centred care by closely monitoring each patient for any adverse event following serotonergic antidepressant prescription.

Secondly, studies have shown that individuals with major depression in COPD are most likely to decline antidepressant drug therapy, due to concerns of stigma, misconceptions about depression, deficiency of adequate support, and fear of adverse events such as nausea, dry mouth, diarrhoea and somnolence [30]. A recent collaborative care study [31] in a primary care setting employed depression care managers (e.g. social workers, nurses and psychologists) to intervene with older adults with major depression. The care managers worked closely with the patients to identify treatment barriers, facilitate participation in a rehabilitation programme and encourage prescribed antidepressants using algorithm-based depression care for 2 years. Mortality risk in the intervention group was $24 \%$ less than the usual care group and similar to 
older adults without depression. In a similar vein, a multicomponent, case manager-led intervention [32] included an action plan for the management of acute exacerbation of COPD. This case manager intervention did not reduce the frequency of emergency department visits or hospital admissions but reduced the mortality rate by almost half compared to usual care [32].

Thirdly, a number of factors reduce adherence to antidepressant drug therapy, including fear of sideeffects, doctor-patient relationship and/or communication, lack of social support and hopelessness. It is paramount when prescribing an SSRI/SNRI to follow the principle of "start low and go slow", gradually increasing to a therapeutic dose level a patient will adequately tolerate. Furthermore, it is important to counsel and empower patients about depression prior to initiating an SSRI/SNRI, and also about both the potential side-effects related to their COPD and how to manage the side-effects. A follow-up visit every 4 weeks, especially in the early stages of antidepressant therapy, is essential in monitoring patient adherence and progress. Thereafter, either face-to-face or telephone contacts periodically are a worthwhile venture.

Strengths of the study include the large number of participants enrolled with the control group and the robust methodology utilised to analyse the data. However, the findings should be interpreted cautiously in the light of some study limitations, as already acknowledged by the investigators. The retrospective identification of patients from the database with COPD reinforces the utility of these data in generating new hypotheses but not for determining firm causal relationships. These administrative data did not allow ascertainment of the indication for antidepressant treatment. The increased mortality risk identified with SSRI/SNRI may be additive to the mortality associated with the chronicity of respiratory impairment, severe dyspnoea, advanced stages of COPD and need for long-term oxygen therapy, which are all markers of disease severity. The authors should be applauded for their subsequent sensitivity analyses, which controlled for 40 relevant covariates to mitigate the potential confounders to increased mortality. Unfortunately, the database also lacks lung function tests, smoking status, alcohol and indices of sleep deprivation, which further limits the generalisability of the findings. Nevertheless, the results highlight that patients with COPD and a concomitant diagnosis of depression are at increased risk of hospitalisation and premature mortality. Unremitted depression (even after SSRI/SNRI therapy) is most likely to reduce motivation for both seeking help and adhering to treatment, and to increase the burden of disability, further undermining good care. Finally, the detailed analysis of both community patients and long-term

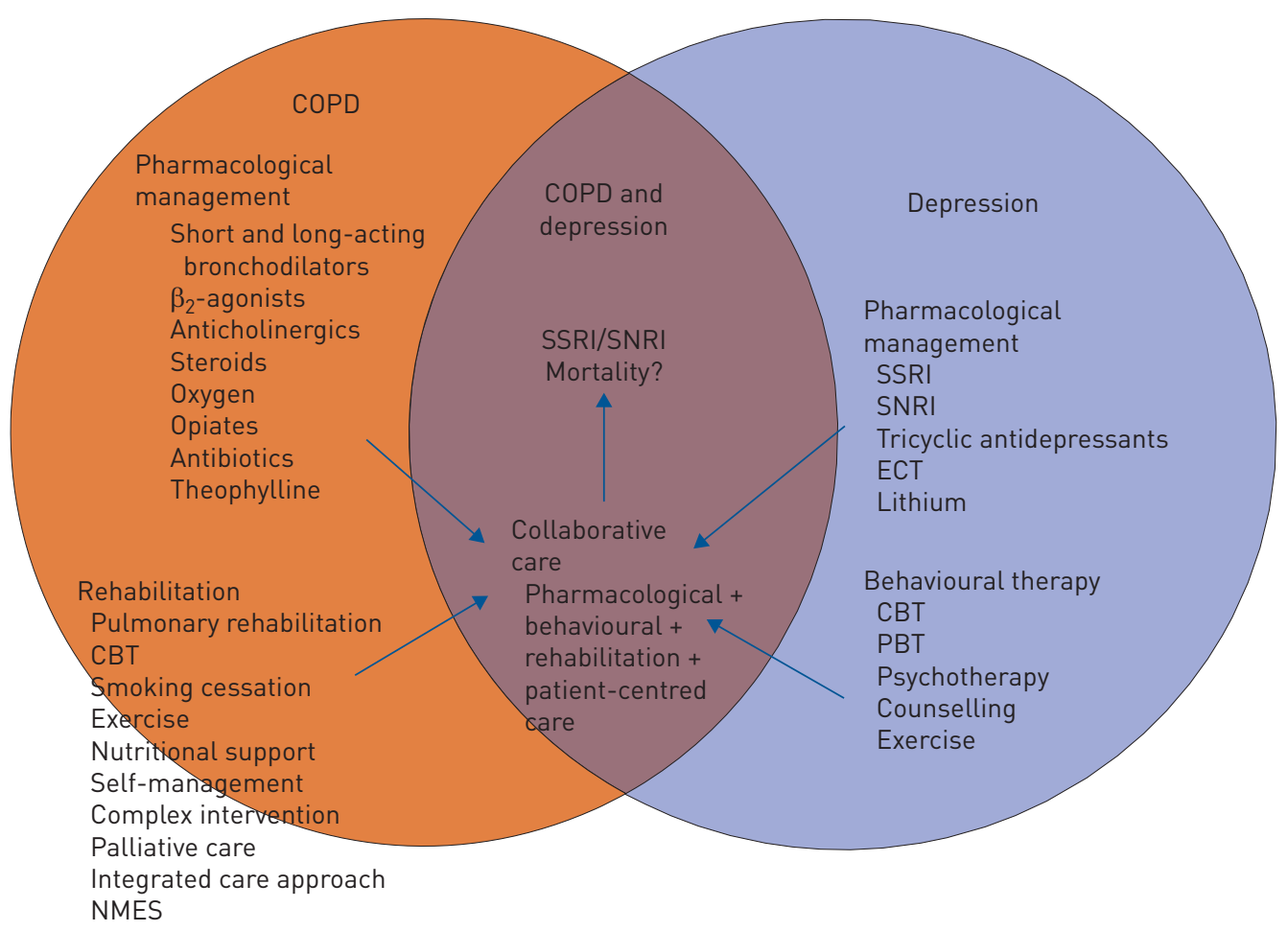

FIGURE 1 Collaborative care for management of depression and chronic obstructive pulmonary disease (COPD). CBT: cognitive behavioural therapy; NMES: neuromuscular electrical stimulation; SSRI: selective serotonin reuptake inhibitor; SNRI: serotonin-noradrenaline reuptake inhibitor; ECT: electroconvulsive therapy; PBT: problem-based therapy. 
care residents (likely to be sicker, and with higher prevalence of psychiatric disorders and benzodiazepine use), excluding patients receiving hospice or palliative care, yielded similar findings, relating antidepressants to excess morbidity and mortality.

In managing depression in patients with chronic diseases, antidepressants should never be the sole treatment. Individuals with mild-to-moderate depression may equally benefit from mindfulness or cognitive behavioural therapy (CBT), and individuals who prefer CBT [33] to antidepressants should have prompt access to behavioural therapy services. In addition, both exercise therapy and comprehensive pulmonary rehabilitation [34], as well as complex interventions [35], have shown promising short-term results in ameliorating depression and anxiety in patients with COPD. Many unanswered questions remain, conceivably the most noteworthy of which is how to predict which patients are most likely to derive benefit (remission) from serotonergic antidepressant drugs in patients with COPD. Furthermore, careful consideration and vigilance are required in the use (prescribing) of benzodiazepines as they relate with higher risk of emergency care visits and hospitalisation in older adults with COPD [22].

In summary, treatment of depression in older patients with COPD is complex and challenging, including potential drug interactions. The findings by Vozoris et al. [27] that SSRI/SNRI therapy is related to elevated risk of disease burden and mortality underscores the importance of having a collaborative care, patient-centred approach, as shown in figure 1, to manage depression, and reduce acute exacerbations, hospitalisations, and mortality in patients with COPD. Prospective, randomised controlled trials are needed to establish whether SSRI/SNRI therapy is causal or merely a marker for elevated mortality risk in patients with COPD before denying our patients with major depression this valuable, efficacious therapy. As depression and COPD are so closely interconnected through socioeconomic status, psychological and behavioural factors, a multimodal treatment approach that interrupts the pathways linking depression and excess mortality remains a worthy endeavour.

Conflict of interest: None declared.

\section{References}

1 GBD 2015 Mortality and Causes of Death Collaborators. Global, regional, and national deaths, prevalence, disability-adjusted life years, and years lived with disability for chronic obstructive pulmonary disease and asthma, 1990-2015: a systematic analysis for the Global Burden of Disease Study 2015. Lancet Respir Med 2017; 5: 691-706.

2 Gibson GJ, Loddenkemper R, Sibille Y, et al., eds. European Lung White Book. Sheffield, European Respiratory Society, 2013.

3 Gibson GJ, Loddenkemper R, Lundback B, et al. Respiratory health and disease in Europe: the new European Lung White Book. Eur Respir J 2013; 42: 559-563.

4 Yohannes AM, Willgoss TG, Baldwin RC, et al. Depression and anxiety in chronic heart failure and chronic obstructive pulmonary disease: prevalence, relevance, clinical implications and management principles. Int $J$ Geriatr Psychiatry 2010; 25: 1209-1221.

5 Yohannes AM, Müllerová $\mathrm{H}$, Hanania NA, et al. Long-term course of depression trajectories in patients with COPD: A 3-year follow-up analysis of the evaluation of COPD longitudinally to identify predictive surrogate endpoints cohort. Chest 2016; 149: 916-926.

6 Hill K, Geist R, Goldstein RS, et al. Anxiety and depression in end-stage COPD. Eur Respir J 2008; 31: 667-677.

7 Maurer J, Rebbapragda V, Borson S, et al. ACCP workshop panel on anxiety and depression in COPD. Anxiety and depression in COPD: current understanding, unanswered questions and research needs. Chest 2008; 134: Suppl. 4, 43S-56S.

8 Singh G, Zhang W, Kuo Y-F, et al. Association of psychological disorders with 30-day readmission rates in patients with COPD. Chest 2016; 149: 905-915.

9 Lyer AS, Bhatt SP, Garner JJ, et al. Depression is associated with readmission for acute exacerbation of chronic obstructive pulmonary disease. Ann Am Thorac Soc 2016; 13: 197-203.

10 Chailleux E, Fauroux B, Binet F, et al. Predictors of survival in patients receiving domiciliary oxygen therapy or mechanical ventilation. A 10-year analysis of ANTADIR Observatory. Chest 1996; 109: 741-749.

11 Yohannes AM, Baldwin RC, Connolly MJ. Predictors of 1-year mortality in patients discharged from hospital following acute exacerbation of chronic obstructive pulmonary disease. Age Ageing 2005; 34: 491-496.

12 Collins PF, Stratton RJ, Kurukulaaratchy RJ, et al. Influence of deprivation on health care use, healthcare costs, and mortality in COPD. Int J Chron Obstruct Pulmon Dis 2018; 13: 1289-1296.

13 Marti S, Muñoz X, Rios J, et al. Body weight and comorbidity predict mortality in COPD patients treated with oxygen therapy. Eur Respir J 2006; 27: 689-696.

14 Pavlov N, Haynes AG, Stucki A, et al. Long-term oxygen therapy in COPD patients: population-based cohort study on mortality. Int J Chron Obstruct Pulmon Dis 2018; 13: 979-988.

15 Laforest L, Roche N, Devouassoux G, et al. Frequency of comorbidities in chronic obstructive pulmonary disease, and impact on all-cause mortality: a population-based cohort study. Respir Med 2016; 117: 33-39.

16 Lou P, Chen P, Zhang P, et al. Effects of smoking, depression and anxiety on mortality in COPD patients: a prospective study. Respir Care 2014; 59: 612-618.

17 Koehorst-Ter Huurne K, Groothuis-Oudshoorn CG, van der Valk PD, et al. Association between poor therapy adherence to inhaled corticosteroids and tiotropium and morbidity and mortality in patients with COPD. Int $J$ Chron Obstruct Pulmon Dis 2018; 13: 1683-1690.

18 Furlanetto KC, Donária L, Schneider LP, et al. Sedentary behavior is an independent predictor of mortality in subjects with COPD. Respir Care 2017; 62: 579-587. 
19 Yohannes AM, Raue PJ, Kanellopoulos D, et al. Predictors of all-cause mortality in patients with severe COPD and major depression admitted to a rehabilitation hospital. Chest 2016; 149: 467-473.

20 Papaioannou AI, Bartziokas K, Tsikrika S, et al. The impact of depressive symptoms on recovery and outcome of hospitalised COPD exacerbations. Eur Respir J 2013; 41: 815-823.

21 Maters GA, de Voogd JN, Sanderman R, et al. Predictors of all-cause mortality in patients with stable COPD: medical co-morbid conditions or high depressive symptoms. COPD 2014; 11: 468-474.

22 Vozoris NT, Fischer HD, Wang X, et al. Benzodiazepine drug use and adverse respiratory outcomes among older adults with COPD. Eur Respir J 2014; 44: 332-340.

23 Vozoris NT, Wang X, Fischer HD, et al. Incident opioid drug use and adverse respiratory outcomes among older adults with COPD. Eur Respir J 2016; 48: 683-693.

24 Qian J, Simoni-Wastila L, Rattinger GB, et al. Associations of depression diagnosis and antidepressant treatment with mortality among young and disable Medicare beneficiaries with COPD. Gen Hosp Psychiatry 2013; 35: 612-618.

25 National Institute for Health and Care Excellence. Depression in adults: the treatment and management of depression in adults. www.nice.org.uk/CG90 Date last accessed: June 10, 2018. Date last updated: April 2018.

26 Yohannes AM, Alexopoulos GS. Pharamacological treatment of depression in older patients with chronic obstructive pulmonary disease: impact on the course of the disease and health outcomes. Drugs Aging 2014; 31: 483-492.

27 Vozoris NT, Wang X, Austin PC, et al. Serotonergic antidepressant use and morbidity and mortality among older adults with COPD. Eur Respir J 2018; 52: 1800475

28 Stewart JC, Perkins AJ, Callahan CM. Effect of collaborative care for depression on risk of cardiovascular events: data from the IMPACT randomized controlled trial. Psychosom Med 2014; 76: 29-37.

29 Richards DA, Hill JJ, Gask L, et al. Clinical effectiveness of collaborative care for depression in UK primary care (CADET): cluster randomised controlled trial. BMJ 2013; 347: f4913.

30 Yohannes AM, Connolly MJ, Baldwin RC. A feasibility study of antidepressant drug therapy in depressed elderly patients with chronic obstructive pulmonary disease. Int J Geriatr Psychiatry 2001; 16: 451-454.

31 Gallo JJ, Morales KH, Bogner HR, et al. Long term effect of depression care management on mortality in older adults: follow-up of cluster randomized controlled trial in primary care. BMJ 2013; 346: f2570.

32 Rose L, Istanboulian L, Carriere L, et al. Program of Integrated Care for Patients with Chronic Obstructive Pulmonary Disease and Multiple Comorbidities (PIC COPD $^{+}$): a randomised controlled trial. Eur Respir J 2018; 51: 1701567.

33 Farver-Vestergaard I, O’Toole MS, O’Connor M, et al. Mindfulness-based cognitive therapy in COPD: a cluster randomized controlled trial. Eur Respir J 2018; 51: 1702082.

34 Spruit MA, Singh SJ, Rochester CL, et al. Pulmonary rehabilitation for patients with COPD during and after an exacerbation-related hospitalisation: back to the future? Eur Respir J 2018; 51: 1701312.

35 Coventry PA, Bower P, Keyworth C, et al. The effect of complex interventions on depression and anxiety in chronic obstructive pulmonary disease: systematic review and meta-analysis. PLoS One 2013; 8: e60532. 